\title{
Supplement of: Stable accumulation patterns around Dome C, East Antarctica, over the last glacial cycle
}

\author{
Marie G.P. Cavitte ${ }^{1,2}$, Frédéric Parrenin ${ }^{3}$, Catherine Ritz ${ }^{3}$, Duncan A. Young ${ }^{1}$, \\ Donald D. Blankenship ${ }^{1,2}$, Massimo Frezzotti ${ }^{4}$, and Jason. L. Roberts ${ }^{5,6}$ \\ ${ }^{1}$ Institute for Geophysics, Jackson School of Geosciences, University of Texas at Austin, Austin, \\ Texas, USA \\ ${ }^{2}$ Department of Geological Sciences, Jackson School of Geosciences, University of Texas at \\ Austin, Austin, Texas, USA \\ ${ }^{3}$ Univ. Grenoble Alpes, CNRS, IRD, IGE, F-38000 Grenoble, France \\ ${ }^{4}$ ENEA, Agenzia Nazionale per le nuove tecnologie, l'energia e lo sviluppo sostenibile, Rome, Italy \\ ${ }^{5}$ Australian Antarctic Division, Kingston, Tasmania 7050, Australia \\ ${ }^{6}$ Antarctic Climate \& Ecosystems Cooperative Research Centre, University of Tasmania, Hobart, \\ Tasmania 7001, Australia
}

Correspondence to: Marie G.P. Cavitte (mariecavitte@gmail.com)

\section{Abstract.}

\section{Introduction}

\section{S1: Bed topography in the Dome $\mathrm{C}$ region}

Figure S1 shows Bedmap2 topography with the Young et al. (in review) refined bed elevation grid

obtained using the OIA survey radar data (outlined with a dashed rectangle). The surface contours highlight the areas of reduced surface slope. The same areas of higher accumulation discussed in the manuscript (Fig. 3 and 5 of the manuscript) are highlighted here. The accumulation variations we observe are co-located with significant bedrock relief changes, which reach e.g. $\sim 2000 \mathrm{~m}$ for the Concordia Ridge (CR) escarpment, and $\sim 500 \mathrm{~m}$ for the south side of the Little Dome C massif (LDCm).

\section{S2: Reconstructed accumulation rate uncertainties}

The calculated time-averaged accumulation rate $(\bar{a})$ uncertainties are plotted for the entire region in Fig. \$2, and have an average value of $0.16 \mathrm{~mm}$-we $\mathrm{yr}^{-1}$. The Metropolis-Hastings (MH) iterations calculate a steady-state uncertainty which takes into account the age uncertainty of the radar isochrones, a combination of the radar depth uncertainties translated to an age uncertainty (Cavitte et al. 2016) and the AICC12 ice core chronology uncertainties (Veres et al., 2013; Bazin et al. 
2013). The calculated uncertainties are relatively small and uniform over the LDCm, remaining below $0.3 \mathrm{~mm}$-we $\mathrm{yr}^{-1}$. They more than double east of the $\mathrm{CR}$, where the rough topography limits the applicability of the 1D pseudo-steady ice flow model.

\section{S3: Slope in the Prevailing Wind Direction (SPWD) in the Dome $\mathrm{C}$ region}

Figure $\mathrm{S} 3$ shows surface slopes in the prevailing wind direction (SPWD) calculated from Bamber et al. (2009) surface topography and ECMWF 5-year average wind directions. Time-averaged accumulation rates $\bar{a}$ as shown in Fig. 3 of the main manuscript are plotted on top. We see that the small-scale areas of high accumulation observed are co-located with areas of markedly reduced

25 SPWD values with respect to the surrounding values ( 1.2-1.5 $\times 10^{-3}$ of SPWD change). This fits well with the model put forward by Frezzotti et al. (2007) over Talos Dome where accumulation increases when the SPWD decreases. We are only referring to the absolute magnitude of the SPWD values as described in Frezzotti et al. (2007), but there is also an interesting polarity of the SPWD values across the divide. The prevailing wind direction over the area is more or less along the long axis of Dome $\mathrm{C}$ flowing from further up the ice divide towards Dome C (Frezzotti et al., 2005: Urbini et al. 2008).

\section{Conclusions}




\section{References}

Bamber, J., Gomez-Dans, J., and Griggs, J.: A new $1 \mathrm{~km}$ digital elevation model of the Antarctic derived from combined satellite radar and laser data-Part 1: Data and methods, The Cryosphere, 3, 101-111, doi $10.5194 /$ tc-3-101-2009. 2009.

Bazin, L., Landais, A., Lemieux-Dudon, B., Toyé Mahamadou Kele, H., Veres, D., Parrenin, F., Martinerie, P., Ritz, C., Capron, E., Lipenkov, V., et al.: An optimized multi-proxy, multi-site Antarctic ice and gas orbital chronology (AICC2012): 120-800 ka, Climate of the Past, 9, 1715-1731, doi:10.5194/cp-9-17152013, 2013

Cavitte, M. G., Blankenship, D. D., Young, D. A., Schroeder, D. M., Parrenin, F., Lemeur, E., Macgregor, J. A., and Siegert, M. J.: Deep radiostratigraphy of the East Antarctic plateau: connecting the Dome C and Vostok ice core sites, Journal of Glaciology, 62, 323-334, 2016.

Fretwell, P., Pritchard, H. D., Vaughan, D. G., Bamber, J., Barrand, N., Bell, R., Bianchi, C., Bingham, R., Blankenship, D., Casassa, G., et al.: Bedmap2: improved ice bed, surface and thickness datasets for Antarctica, The Cryosphere, 7, 2013.

Frezzotti, M., Pourchet, M., Flora, O., Gandolfi, S., Gay, M., Urbini, S., Vincent, C., Becagli, S., Gragnani, R., Proposito, M., et al.: Spatial and temporal variability of snow accumulation in East Antarctica from traverse data, Journal of Glaciology, 51, 113-124, 2005.

Frezzotti, M., Urbini, S., Proposito, M., Scarchilli, C., and Gandolfi, S.: Spatial and temporal variability of surface mass balance near Talos Dome, East Antarctica, Journal of Geophysical Research: Earth Surface, $112,2007$.

Urbini, S., Frezzotti, M., Gandolfi, S., Vincent, C., Scarchilli, C., Vittuari, L., and Fily, M.: Historical behaviour of Dome $\mathrm{C}$ and Talos Dome (East Antarctica) as investigated by snow accumulation and ice velocity measurements, global and planetary change, 60, 576-588, 2008.

Veres, D., Bazin, L., Landais, A., Toyé Mahamadou Kele, H., Lemieux-Dudon, B., Parrenin, F., Martinerie, P., Blayo, E., Blunier, T., Capron, E., et al.: The Antarctic ice core chronology (AICC2012): an optimized multiparameter and multi-site dating approach for the last 120 thousand years, Climate of the Past, 9, 1733-1748, doi:10.5194/cp-9-1733-2013 2013.

60 Young, D. A., Roberts, J. L., Ritz, C., Frezzotti, M., Quartini, E., Cavitte, M. G. P., Tozer, C. R., Steinhage, D., Urbini, S., Corr, H. F. J., Van Ommen, T., and Blankenship, D. D.: High resolution boundary conditions of an old ice target near Dome C, Antarctica, The Cryosphere Discussions, in review. 


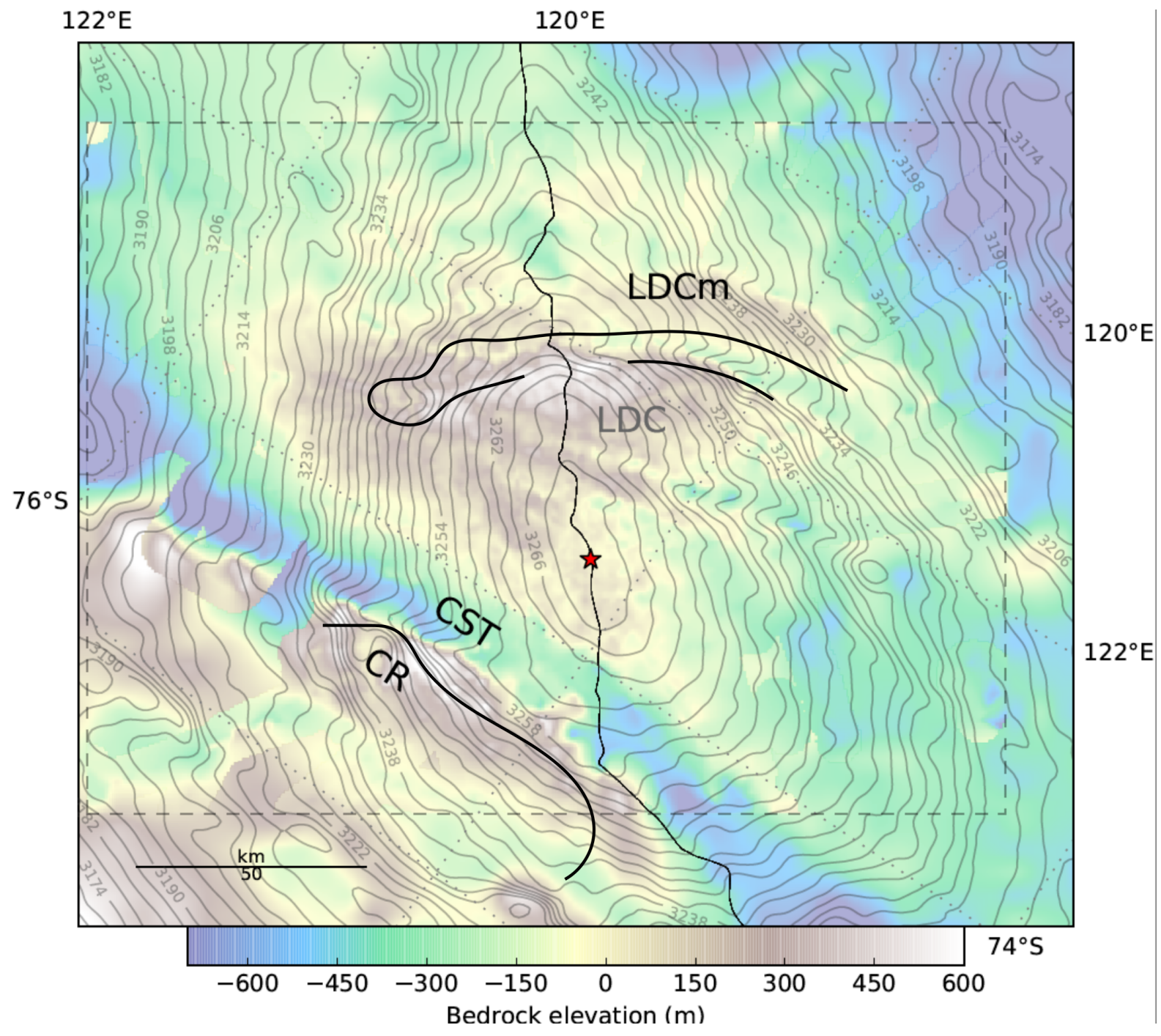

Figure 1. Bedmap2 bedrock elevations (Fretwell et al. 2013) with recompiled OIA radar bed elevations (Young et al. in review) delimited by a dashed rectangle. The same black lines highlighting the areas of small-scale high accumulation as on Fig. 3 are drawn to highlight the influence of the bed on small-scale accumulation variations. Gray lines are Bamber et al. (2009) surface elevations, a black line locates the ice divide. A red star locates the EPICA Dome C ice core. LDC locates the gentle secondary surface dome, LDCm locates the Little Dome C massif under the densest radar lines, CR locates the Concordia Ridge steep escarpment along the Concordia Subglacial Trench (CST). 

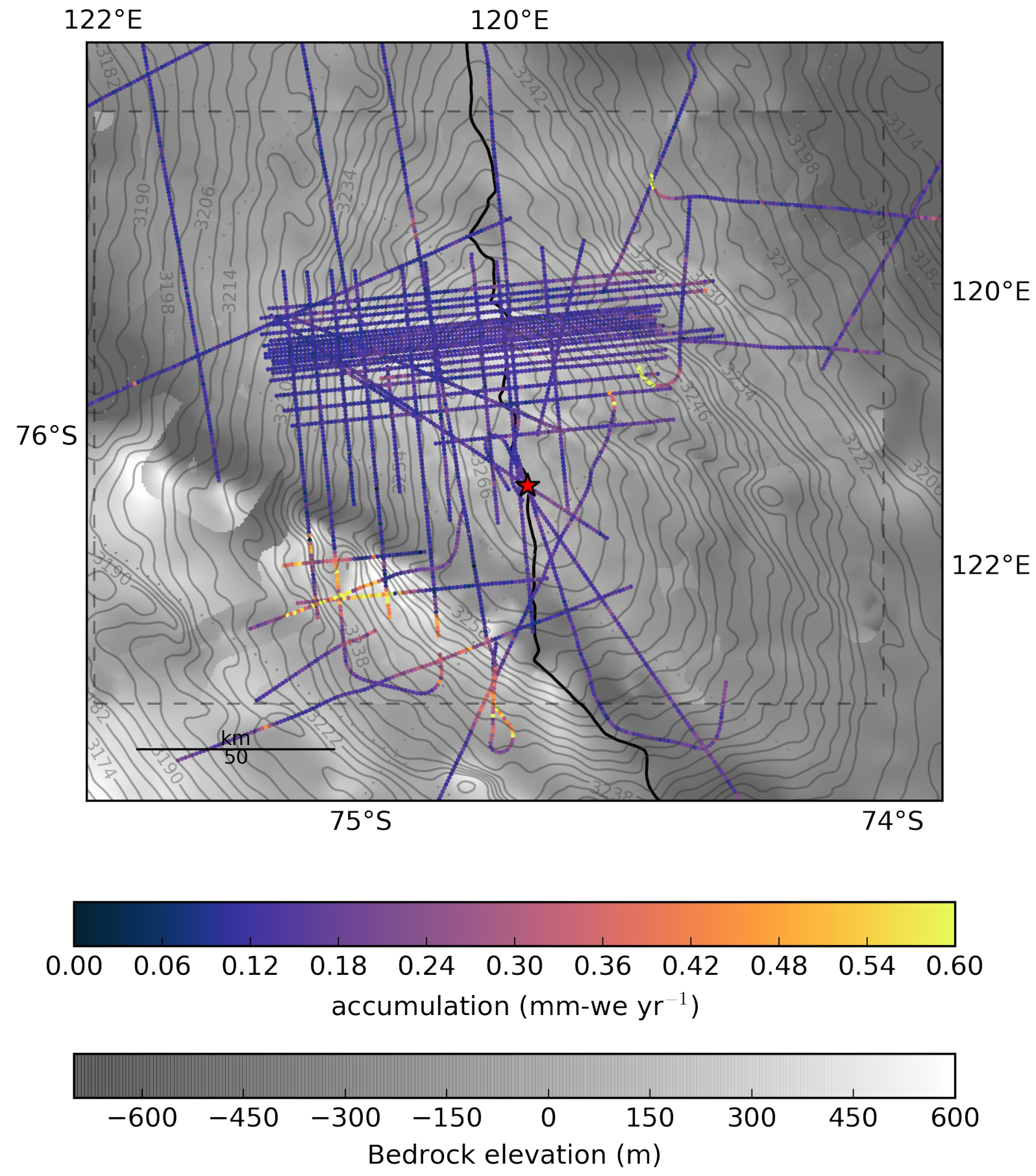

Figure 2. Time-averaged accumulation rate uncertainties over the Dome $\mathrm{C}$ region. Uncertainties are low over the $\mathrm{LDCm}$, but increase east of the $\mathrm{CR}$ area. Background is the same as in Fig. S1 in grayscale. 

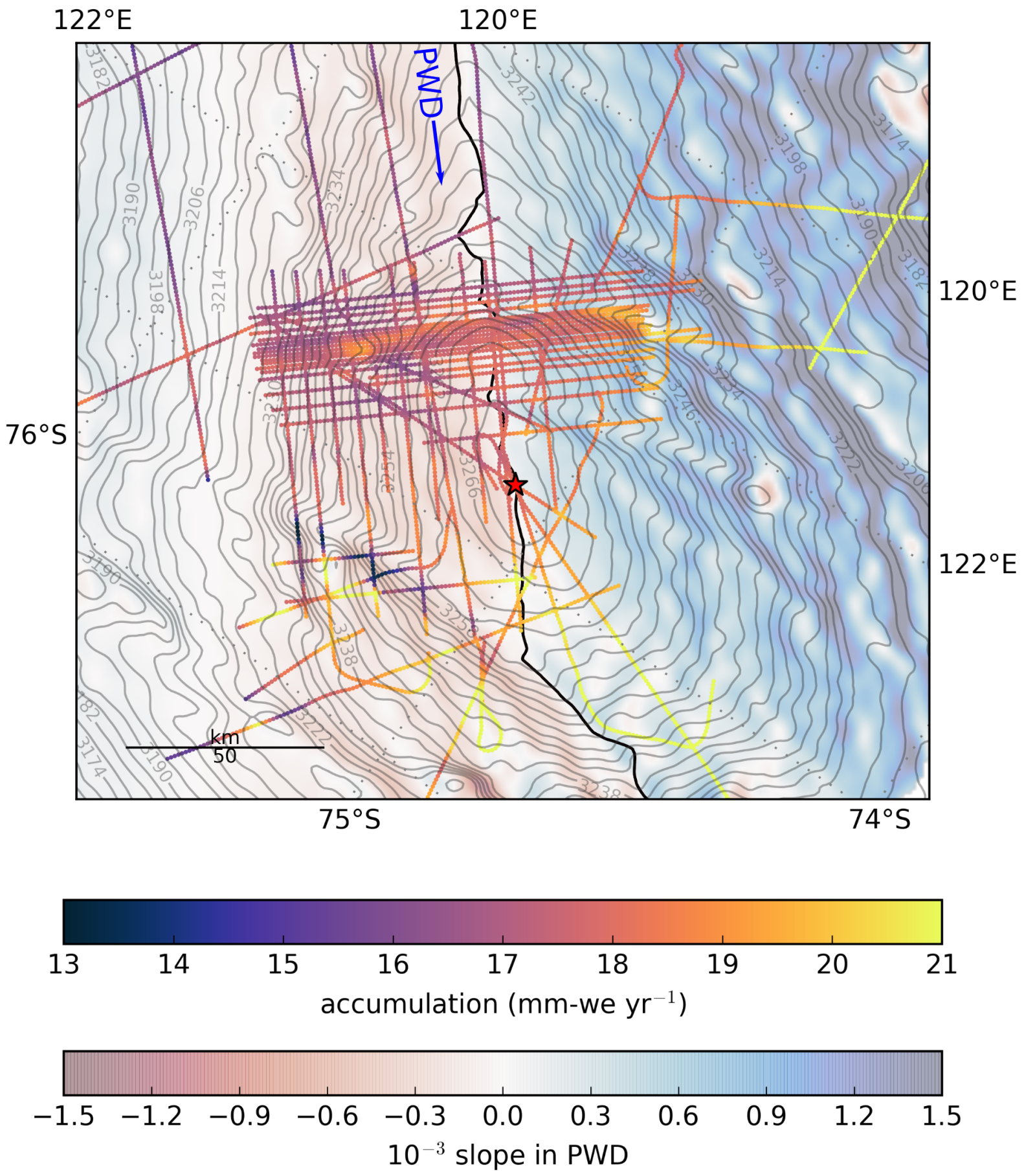

Figure 3. Time-averaged accumulation rates $\bar{a}$ over the Dome $\mathrm{C}$ region, overlain on surface slope in the prevailing wind direction (SPWD). The prevailing wind direction (PWD) is indicated by a blue arrow. 